\title{
In vitro antioxidant potential study of some synthetic quinoxalines
}

\author{
Hossain $\mathrm{MM}^{1}$, Hossain $\mathrm{MM}^{2}$, Muhib $\mathrm{MH}^{1}$, Mia $\mathrm{MR}^{1}, \operatorname{Kumar} \mathrm{S}^{3}$, Wadud $\mathrm{SA}^{4}$ \\ ${ }^{1}$ Associate Professor, Department of Chemistry, Jahangirnagar University, Savar, Dhaka, \\ ${ }^{2}$ Student, Department of Chemistry, Jahangirnagar University, Savar, Dhaka, \\ ${ }^{3}$ Department of Pharmacy, Jahangirnagar University, Savar, Dhaka, \\ ${ }^{4}$ Department of Ophthalmology, Bangabhandhu Sheikh Mujib Medical University, Dhaka. \\ Email: chemmamun2@yahoo.com
}

\begin{abstract}
In continuation of our study the in vitro antioxidant activity of some novel quinoxaline derivatives was investigated by 1,1-diphenyl-2-picrylhydrazyl (DPPH) method with respect to ascorbic acid. To determine the antioxidant activity, a number of substituted indoxyls (3A-G), cyclic ketones (2A-G), and quinoxalines $(1 \mathrm{~A}-\mathrm{G})$ were synthesized by both microwave and conventional heating methods. The present findings revealed that some quinoxalines and their precursors (1D, $1 \mathrm{~F}, 1 \mathrm{G}$ and $2 \mathrm{E}$ ) exhibited a marked scavenging effect on DPPH radical.
\end{abstract}

\section{Introduction}

The recent literatures are enriched with progressive findings about the synthesis and antioxidant activity of fused ring heterocyclic compounds ${ }^{1 \mathbf{a}}$. The structural diversity and biological importance of nitrogenous heterocycles are being made them remarkable synthetic targets over the years and they exist in various natural products ${ }^{\mathbf{1 b}}$. Quinoxalines are an important class of nitrogen containing heterocycles with a variety of biological activities. In particular, quinoxalines were found as core units in a number of biologically active compounds. These include anticancer ${ }^{2,3}$ antibacterial $^{4}$, antiviral ${ }^{5}$, anti-inflammatory ${ }^{\mathbf{6}}$, anti HIV $^{\mathbf{7 , 8}}$, and antihelmintic activities ${ }^{9}$. Antioxidant compounds play an important role as a health-protecting factor. Scientific evidence suggests that antioxidants reduce the risk for chronic diseases including cancer and heart disease. Primary sources of naturally occurring antioxidants are whole grains, fruits and vegetables ${ }^{\mathbf{1 0 - 1 2}}$. Plant sourced food antioxidants like vitamin $\mathrm{C}$, vitamin $\mathrm{E}$, carotenes, phenolic acids phytate and phytoestrogens have been recognized as having the potential to reduce disease risk $^{\mathbf{1 3}}$. The main characteristic of an antioxidant is its ability to trap free radicals. Highly reactive free radicals and oxygen species are present in biological systems from a wide variety of sources. These free radicals may oxidize nucleic acids, proteins, lipids or DNA and can initiate degenerative disease. Antioxidant compounds like phenolic acids, polyphenols and flavonoids scavenge free radicals such as peroxide, hydroperoxide or lipid peroxyl and thus inhibit the oxidative mechanisms that lead to degenerative diseases. In our eye sight, on the other hand, the natural lens is made of mostly protein and water. As we age, the proteins break down and form clumps that cause the lens to thicken and disrupt our vision. The process occurs slowly, so that, in the early stages, people will not notice vision changes $^{14,15}$. Someone may need frequent changes in his glasses prescription to maintain clear vision, but in the advanced stages, prescription glasses will not improve. Although antioxidants are versatile in their physiological action they cannot treat or remove cataracts, and these nutrients cannot restore vision from cataract damage. Despite this, antioxidants may help prevent the breakdown of proteins in the lens, and this may help prevent or slow down the growth of cataracts ${ }^{16-18}$. Therefore, in continuation of our study we synthesized some indole-based quinoxaline compounds, which may function as food supplements, for the test to show any antioxidant activity. Accordingly numerous quinoxaline compounds were synthesized by means of reductive cyclization reaction from their precursors in fairly good yield.

\section{Materials and Methods}

Synopsis of the chemical structures of synthesized compounds is shown in scheme 1 . 

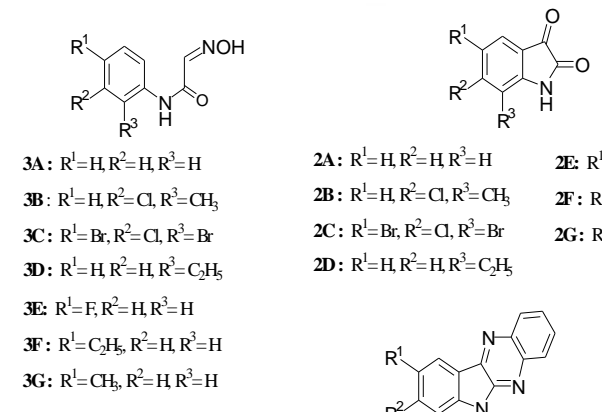

2A: $\mathrm{R}^{1}=\mathrm{H}, \mathrm{R}^{2}=\mathrm{H}, \mathrm{R}^{3}=\mathrm{H}$

2E: $R^{1}=F, R^{2}=H, R^{3}=H$

2B: $\mathrm{R}^{1}=\mathrm{H}, \mathrm{R}^{2}=\mathrm{C}, \mathrm{R}^{3}=\mathrm{CH}_{3}$

2C: $\mathrm{R}^{1}=\mathrm{Br}, \mathrm{R}^{2}=\mathrm{C}, \mathrm{R}^{3}=\mathrm{Br}$

2D: $\mathrm{R}^{1}=\mathrm{H}, \mathrm{R}^{2}=\mathrm{H}, \mathrm{R}^{3}=\mathrm{C}_{2} \mathrm{H}_{5}$

2F: $\mathrm{R}^{1}=\mathrm{C}_{2} \mathrm{H}_{5}, \mathrm{R}^{2}=\mathrm{H}, \mathrm{R}^{3}=\mathrm{H}$

2G: $\mathrm{R}^{1}=\mathrm{CH}_{3}, \mathrm{R}^{2}=\mathrm{H} \mathrm{R}^{3}=\mathrm{H}$

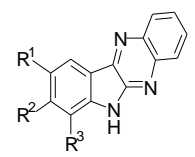

1A: $\mathrm{R}^{1}=\mathrm{H}, \mathrm{R}^{2}=\mathrm{H}, \mathrm{R}^{3}=\mathrm{H}$

1E: $R^{1}=F, R^{2}=H, R^{3}=H$

IB: $\mathrm{R}^{1}=\mathrm{H}, \mathrm{R}^{2}=\mathrm{C}, \mathrm{R}^{3}=\mathrm{CH}_{3}$

1F: $\mathrm{R}^{1}=\mathrm{C}_{2} \mathrm{H}_{5}, \mathrm{R}^{2}=\mathrm{H}, \mathrm{R}^{3}=\mathrm{H}$

1C: $\mathrm{R}^{1}=\mathrm{Br}, \mathrm{R}^{2}=\mathrm{Cl}, \mathrm{R}^{3}=\mathrm{Br}$

D: $\mathrm{R}^{1}=\mathrm{H}_{1} \mathrm{R}^{2}=\mathrm{H}^{3}=\mathrm{C}_{2} \mathrm{H}_{5}$

1G: $\mathrm{R}^{1}=\mathrm{CH}_{3}, \mathrm{R}^{2}=\mathrm{H}, \mathrm{R}^{3}=\mathrm{H}$

Scheme 1

\section{Anti-Oxidant Potential}

It is well known that free radicals cause auto oxidation of unsaturated lipids in food. In addition, antioxidants are known to interrupt the free-radical chain of oxidation and to donate hydrogen from phenolic hydroxy groups, thereby, forming stable free radicals, which do not initiate or propagate further oxidation of lipids ${ }^{\mathbf{1 9}}$. DPPH is a stable free radical containing an odd electron in its structure and usually utilized for detection of the radical scavenging activity in chemical analysis. The aliquot of the different concentrations (5-500 $\mu \mathrm{g} / \mathrm{ml}$ ) of the test sample is added to $3 \mathrm{ml}$ of a $0.004 \%$ ethanolic solution of DPPH. Absorbance at $517 \mathrm{~nm}$ is determined after $30 \mathrm{~min}$, and $\mathrm{IC}_{50}$ (Inhibitory conc. 50\%) is also determined. $\mathrm{IC}_{50}$ value denotes the concentration of sample required to scavenge $50 \%$ of the DPPH free radicals. The formula used for \% inhibition is as follows:

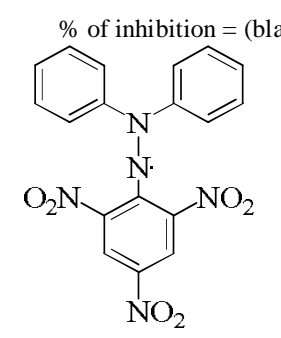

DPPH radical

$$
\text { k OD - Sample OD/Blank OD) } \times 100
$$

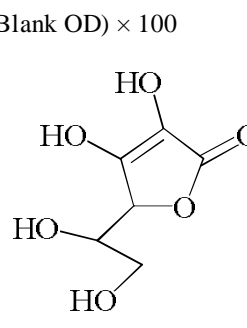

Ascorbic Acid
Scheme 2

\section{Sampling, screening and $\mathrm{IC}_{50}$ calculation}

At first 5 test tubes were taken to make aliquots of 5 different concentrations level $(5,10,50,100$ and $500 \mu \mathrm{g} / \mathrm{ml}$ ). Tested sample and ascorbic acid were weighed 3 times and dissolved in ethanol to make the required concentrations by dilution technique. DPPH was weighed and dissolved in ethanol to make $0.004 \%$ (w/v) solution. To make homogeneous solutions of the tested samples, magnetic stirrer was used. After making the desired concentrations, $2 \mathrm{ml}$ of $0.004 \%$ DPPH solution was applied on each test tube by using pipette. The room temperature was recorded and kept the test tubes for 30 minutes in light exposure to complete the reactions. DPPH was also applied on the blank test tubes at the same time where only ethanol was taken as blank. After 30 mins, absorbance of each test tube was determined by UV spectrophotometer. Then \% inhibitions were plotted against log concentration of each of the test sample. Then $\mathrm{IC}_{50}$ was calculated from the graph. The experiment was performed in duplicate and average absorption was noted for each concentration. Ascorbic acid was used as a positive control. Calculated antioxidant data of all the test samples were summarized in Table I.

Table 1: Relative antioxidant potential of synthesized compounds

\begin{tabular}{lll}
\hline Compound No & $\mathrm{IC}_{50}$ Value $\mu \mathrm{g} / \mathrm{ml}$ & Remarks \\
\hline 1A & 22826.00 & Less active \\
1B & 878.07 & Moderately active \\
1C & 1223.21 & Less active \\
1D & 606.42 & Moderately active \\
1E & 710.19 & Moderately active \\
1F & 606.42 & Moderately active \\
1G & 500.42 & Highly active \\
2A & 749.15 & Moderately active \\
2B & 701.12 & Moderately active \\
2C & 1162.57 & Less active \\
2E & 615.32 & Moderately active \\
3B & 3159.07 & Less active \\
3C & 3029.16 & Less active \\
3D & 2791.23 & Less active \\
\hline
\end{tabular}

*Ascorbic acid as a positive control showed an $\mathrm{IC}_{50}$ value of 49 $(\mu \mathrm{g} / \mathrm{mL})$

The mechanistic approach-free radical scavenging of antioxidants

The 1,1-diphenyl-2-picrylhydrazyl radical has been widely used to evaluate the free radical scavenging capacity of different antioxidants ${ }^{\mathbf{1 9 , 2 0}}$. With this method it is possible to determine the antiradical power of an antioxidant activity by measurement of the decrease in the absorbance of DPPH at $517 \mathrm{~nm}$. Resulting from a color change from purple to yellow the absorbance decreased when the DPPH is scavenged by an antioxidant, through donation of hydrogen to form a stable DPPH molecule. In the radical form this molecule had an absorbance at $517 \mathrm{~nm}$, which disappeared after acceptance of an electron or hydrogen radical from an antioxidant compound to become a stable diamagnetic spin paired molecule. The odd electron in the DPPH free radical gives a strong absorption maximum at 517 $\mathrm{nm}$ and is purple in color. The color turns from purple to yellow as the molar absorptivity (optical density) of the DPPH radical at $517 \mathrm{~nm}$ reduces from 9660 to 1640 when the odd electron of DPPH radical becomes paired with hydrogen radical from 
a free radical scavenging antioxidant to form the reduced DPPH-H. The resulting decolorization is stoichiometric with respect to the number of electrons captured.

\section{Results}

The chemical transformation of aromatic amines to quinoxalines was successfully carried out under microwave irradiation with shortest reaction times beside classical synthesis. Reaction of aromatic amines with chloral hydrate and hydroxyl amine hydrochloride gives isonitrosoacetanilide 3A-G which in turn reacts with concentrated sulfuric acid followed by reductive cyclization reaction to furnish new heterocyclic ring systems $1 \mathrm{~A}-\mathrm{G}$. The target molecules were obtained in fairly good to excellent yields (Scheme 1). An important feature of the procedure is the survival of other existing functional groups within the molecules. The structures of the products were characterized using physical methods such as IR, ${ }^{1} \mathrm{H}-\mathrm{NMR}$ and mass spectrometry. The in vitro antioxidant results of different series of synthesized compounds (1A-G, 2A-C, 2E, and 3B-D) with respect to ascorbic acid were reported in Table I. This study reports the antioxidant activity of quinoxaline derivatives and other series of synthesized heterocyclic compounds. Some of the compounds exhibited a marked scavenging effect on DPPH radical. Amongst the synthesized compounds screened for the antioxidant activity, compound $1 \mathrm{G}$ showed highest activity with respect to ascorbic acid. Some of the compounds showed moderate antioxidant activities and some were unable to show.

\section{Discussion}

As per chemical structural features there were three different types of compounds synthesized under the study area. It is obvious that structural variation brings about the bioactivity and, of course, structural modification on molecules alters the biological activity in a regular trend ${ }^{\mathbf{1 9 2 0}}$. Without exception this has been reflected in the case of our targeted compounds quinoxalines (1A-G), which showed upward tendency of antioxidant activity compared to their precursors such as isatins and oximinoacetanilides. It is presumably due to the higher reducing potential of tetracyclic fused ring system polyaza compounds. On the other hand, isatins (2A-E) and their precursors (3B-D) showed irregular trend in their antioxidant activity. Compound $1 \mathrm{~A}-\mathrm{G}$ especially $1 \mathrm{G}$ was attuned to show greater antioxidant potency. As it mentioned earlier that the antioxidant efficacy of any compound depends strongly on its reducing property and hence quinoxalines $1 \mathrm{~A}-\mathrm{G}$ might have the higher reducing potential. Compounds $1 \mathrm{~A}-\mathrm{G}$ have shown greater propensity in showing antioxidant potency because of their structural and high nitrogen percentage. Although we don't have the exact clarification with regard to their comparatively better antioxidant potency, we have some logical arguments in favor of the fact. Actually, the triaza- part of the fused ring system would be responsible for initiate the free radical scavenging activity due to its $\mathrm{N}-\mathrm{H}$ moieties. It is thought that the halide or alkyl groups in different position in the aromatic moieties have electron releasing affinity, which enhanced the reducing potential of the $\mathrm{N}-\mathrm{H}$ bond through intervening aromatic system in case of the most compound of quinoxalines than their precursors. Due to such structural advantage in compound $1 \mathrm{~A}-\mathrm{G}$ would have higher aptitude to trap radical in a faster rate than the other similar type of molecules. This finding is about the structural variation-differs mainly about the functionality from lactam to quinoxalines. The marked difference of the current study from the previous published work is about the variation of the structural moiety and molecular functionality. When an extension of the ring system is being carried out in getting quinoxalines it facilitates having high percentage of nitrogen within the system. Consequently this class of compounds show marked difference in free radical scavenging potency. Therefore, the strategies in designing and synthesis of indole based compounds and the consequent in vivo screening of those should be the main objective of further investigations. This would lead to the synthesis of short listed target molecules of the active metabolites with potent antioxidant activity.

\section{References}

1. (a) Farghaly TA, Abdel NA, Ragab EA, H. M. Awad HM, Abdalla MM. Synthesis, anti-HCV, antioxidant, and peroxynitrite inhibitory activity of fused benzosuberone derivatives. Eur J Med Chem. 2010; 45(2): 492-500.

(b) Pozharskii AF, Soldatenkov AT, Katritzky AR. Heterocycles in life and society, chichester, UK: John Wiley and Sons; 1997.

2. Wiseloge FW. Survey of anti-malarial drugs, 19411945. In: Armarego WLF, editor. Advances in hetero cyclic chemistry, New York: Academic Press; 1963, 1: 304-370.

3. Burguete A, Pontiki E, Litina DH, Villar R, Vicente E, Solano B. Synthesis and anti-inflammatory/antioxidant activities of some new ring substituted 3-phenyl-1(1,4-di-N-oxide quinoxalin-2-yl)-2-propen-1-one derivatives and of their 4,5-dihydro- $(1 \mathrm{H})$-pyrazole analogues. Bioorg Med Chem Lett. 2007; 17: 64396443. 
4. Lindsley $\mathrm{CW}$, Zhao Z, Leister WH, Robinson RG, Barnett SG, R.E.Defeo-Jones RE. Allosteric Akt (PKB) inhibitors: discovery and SAR of isozyme selective inhibitors. Bioorg Med Chem Lett. 2005; 15: 761-764.

5. Harmenberg J, Akesson-Johansson A, Graslund A, Malmfors T, Bergman J. Wahren B. The mechanism of action of the anti-herpes virus compound 2,3dimethyl-6(2-imethylaminoethyl)-6H-indolo-(2,3b)quinoxaline. Antiviral Research.1991; 15: 193-204.

6. Seitz LE, Suling WJ, Reynolds RC. Synthesis and Evaluation of Several New (2-Chloroethyl) nitrosocarbamates as Potential Anticancer Agents. J Med Chem.2002; 45: 5604-5606.

7. More SV, Sastry MNV, Wang CC, Yao CF. Molecular iodine: a powerful catalyst for the easy and efficient synthesis of quinoxalines. Tet Lett.2005;46:6345-6348.

8. Gris J, Glisoni R, Fabian L, Fernandez B, Moglioni AG. Synthesis of potential chemotherapicquinoxalinone derivatives by biocatalysis or microwave-assisted Hinsberg reaction. Tet Lett. 2008; 49: 1053-1056.

9. Sakata G, Makino K, Kurasawa Y. Regent progress in the quinoxaline chemistry-Synthesis and biological activity. Heterocycles. 1988; 27: 2481-2515.

10. Brand-Willams W, Cuvelier ME, Berset C. Use of a free radical method to evaluate antioxidant activity. Lebensmittel-Wissenschaft \& Technologie. 1995; 28: 25-30.

11. Espin JC, Soler-Rivas C, Wichers HJ. Characterization of total free radical scavenger capacity of vegetable oils and oil fraction using 2,2-diphenyl-1picrylhydrazyl radical. J Agric Food Chem. 2000; 48: 648-656.
12. Yu L. Free radical scavenging properties of conjugated linoleic acids. J Agric Food Chem. 2001; 49: 3452-56.

13. Mattha us B. Antioxidant activity of extracts obtained from residues of different oilseeds. J Agric Food Chem.2002; 50: 3444-52.

14. Wevill M. Epidemiology. Pathophysiology, causes, morphology \& visual effects of cataract. In: Yanoff M, et al. Ophthalmology. 3rd ed. Philadelphia, Pa.: Mosby; 2008.ttp://www.mdconsult. om/das/book/body/ 194686199- 3/0/1869/0.html. Accessed April 12, 2010.

15. Cataract in the adult eye. American Academy of Ophthalmology. http://one.aao.org/asset.axd?id=821 cecfb-85c5-400d-a65f-7a9a727bc163. Accessed April $12,2010$.

16. Ehler JP et al. Acquired cataract. The Wills eye manual: $5^{\text {th }}$ ed. Baltimore, Lippincott Williams and Wilkins. 2008. http://ovidsp.ovid.com/ovidweb.cgi. Accessed April 14, 2010.

17. Guercio JR, et al. Congenital malformations of the eye and orbit. Otolaryngologic Clinics of North American. 2007; 40:113.

18. Abel R. Cataract. In: Rakel D. Integrative Medicine. 2nd ed. Philadelphia, Pa.: Saunders Elsevier; 2007. http://www.mdconsult.com/das/book/body/1946861993/0/ 1494/0. html. Accessed April 12, 2010.

19. Mamun MH, Sukanta KS, Foysal A, Antioxidant potential study of some synthesized N-heterocycles. Bangladesh Med Res Counc Bull. 2009; 35: 49-52.

20. Mamun MH, Rehana A, Mahabub H, Mahmud H, Taksim A, Ehsanul HM. In vitro free radical scavenging activity of some $\beta$-lactams and phenolics. Intl J Pharm Pharmaceutical Sci. 2010; 2: 60-63. 